\title{
Erratum
}

\section{Societal pessimism in Japan, the United States, and The Netherlands- ERRATUM}

PEPIJN VAN HOUWELINGEN

DOI: 10.1017/S1468109916000177. Published by Cambridge University Press 12 August 2016

In the above paper one of the acronyms was expanded incorrectly.

'COB' is mentioned as 'Coordination of Benefits' (page 435) but the correct expansion is the following 'Citizens' Outlooks Barometer'.

\section{Reference}

Houwelingen, V. P. (2016) Societal pessimism in Japan, the United States, and The Netherlands. Japanese Journal of Political Science. 17 (3): pp 427-450. 